Arch. Dis. Childh., 1965, 40, 66.

\title{
THE INFLUENCE OF ANDROGEN TREATMENT ON ULTIMATE HEIGHT IN MALES
}

BY

\author{
GEORGE L. FOSS \\ From The United Bristol Hospitals
}

(RECEIVED FOR PUBLICATION MAY 25, 1964)

For the past 25 years androgens have been used to accelerate growth, particularly in boys backward in development or of short stature. There has been considerable controversy whether such treatment would increase, decrease, or not affect, ultimate height.

In a group of 13 boys aged $5 \frac{1}{2}$ years to 10 years, Sobel, Raymond, Quinn, and Talbot (1956) found that methyl testosterone, 5-40 mg. daily, produced a greater average increase in skeletal age than in height age during the treatment period of two to six months. Skeletal maturation continued to advance at a rate greater than the control rate after treatment was finished, whereas growth increments reverted to average normal within the period of follow-up of two years.

However, Bayley, Gordan, and Lisser (1957) found that methyl testosterone 5 to $30 \mathrm{mg}$. daily (usually $10 \mathrm{mg}$. daily) for an undefined period led to no disproportionate skeletal maturation, and in $\mathbf{2 0}$ cases in which growth was followed to adult stature there was no reduction in ultimate height from that predicted before treatment.

During the past 18 years the growth of a series of boys has been observed, and an analysis has been made of the findings to help elucidate this problem.

\section{Method and Material}

A total of 208 young males are included, and are divided into 120 controls and 88 treated with androgens. All were white, and came from the Bristol area.

The control cases were referred for apparent cryptorchism, gynaecomastia, or obesity. Dietetic restriction was prescribed for some of the latter.

The treated group is sub-divided into three groups: (A) 30 boys whose skeletal age was equivalent to their chronological age, or slightly advanced; (B) 37 boys whose skeletal age was a year or more retarded. (These two groups were treated for cryptorchism, inadequate development compared with their fellows, or for small stature.) (C) 21 cases who were all suffering from infantilism to complete eunuchoidism, and whose skeletal age averaged
6 years' retardation over their mean chronological age (19.57 years).

They were measured on a vertical metal height scale with vernier reading made to my own design (Fig. 1), to the nearest $1 / 16$ in. $(0.15 \mathrm{~cm}$.) in their socks, at one to three-monthly intervals according to whether they were receiving treatment or not. Span was also measured with the same apparatus with the scale in the horizontal position. They were also weighed in trousers, socks, and shirt.

A postero-anterior radiograph was taken of their left hands and wrists at intervals of six months. In the past three years all these serial radiographs have been compared with the standards in Greulich's and Pyle's atlas (1959), and skeletal ages were obtained. Predicted heights have then been found in the appropriate tables of Bayley and Pinneau (1952), according to whether skeletal age was normal or advanced or retarded over a year. For calculation of the figures the initial radiograph of hand and wrist was used to obtain skeletal age and prediction of height. Though many of the growth records were complete, with radiological evidence of epiphysial union, it was necessary to attempt the follow-up of 177 of these cases in order to obtain their ultimate height. Unfortunately it was only possible to obtain this measurement in $54.8 \%$ of the whole series. The ages of these patients in the control and treated Groups A and B when followed up ranged from 24-33 years at final measurement, and with the knowledge of their last assessment of skeletal age it was concluded that growth was complete.

In Group C, 20 cases were the subject of more intensive study. The double check of span and height measurements was confirmed by serial radiographs of the left hand and wrist. The time taken until closure of the epiphyses after the onset of treatment, recorded to the nearest six months, is shown in Table 1. In Case Mo, though growth had ceased, epiphysial closure was not completed until 39 years of age, after a further intensive course of injections of testosterone esters: previously he had been disinclined to have further treatment.

Treatment in Groups A and B has varied from $5-30 \mathrm{mg}$. methyl testosterone for two to 14 months continuously, or in 5 cases intermittently, with doses up to $75 \mathrm{mg}$. daily for 30 months. This steroid was ingested in some cases and absorbed sub-labially in others. 


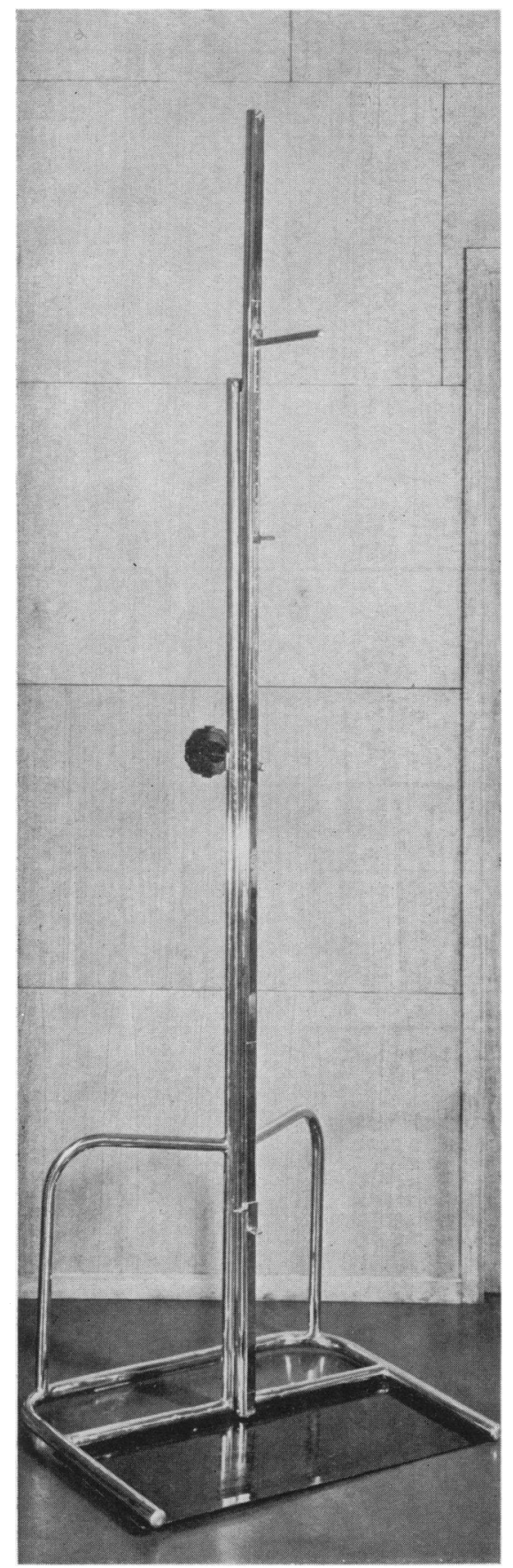

Fig. 1.
In Group $\mathbf{C}$ intensive androgen treatment was given, with implantations of testosterone at regular intervals of 6 months, continuous oral methyl testosterone or fluoxymesterone, or injections of testosterone in the form of short and/or long-acting esters, or combinations of these methods (Table 1), for 2-14 years.

\section{Results}

Controls. In the whole group of 120 cases, when first seen the mean age was $12 \cdot 13$ years (range 9-17 years), mean skeletal age $11 \cdot 81$ years (range 8-18 years), and mean height was $58 \cdot 72$ in. $(149 \mathrm{~cm}$.). The mean predicted height was $70 \cdot 16$ in. $(177 \mathrm{~cm}$.) (S.D. 2.64). Of these, 50 were measured when growth had ceased, with a mean increment of $10 \cdot 57$ in. $(26 \cdot 7 \mathrm{~cm}$.) and a mean ultimate height of $69 \cdot 45 \mathrm{in}$. (176 cm.) (S.D. 2.54). The mean figures, when prediction was made for the 50 cases with a completed growth record, compare closely with those of the whole group of controls (Table 2).

Treated. (A) These boys of similar age to the controls had a similar mean skeletal age, initial height and prediction, and also a mean ultimate height within 0.2 in. $(0.5 \mathrm{~cm}$.) (S.D. 0.91$)$, and a mean total increment of $10 \cdot 69$ in. $(27 \cdot 15 \mathrm{~cm}$.) growth (Table 2).

(B) The mean age was a little higher, 14.46 years, in the completed growth studies with a mean skeletal age of $11 \cdot 92$, so that their skeletal ages were retarded by over 2 years. Mean initial height was an inch less and their mean prediction was nearly 2 inches less than in Group A. Their total growth increment had an average of $9.77 \mathrm{in} .(24.8 \mathrm{~cm}$.), and their mean ultimate height was within 0.5 in. $(1 \cdot 27 \mathrm{~cm}$.) (S.D. 1 22) of the predicted mean (Table 2).

(C) In this series of cases of infantilism (Table 1), intensively treated with androgens for long periods of 2-8 years, the mean age was 19.57 years, and skeletal age $13 \cdot 68$. They were initially taller $63 \cdot 88$ in. $(168 \cdot 25 \mathrm{c} . \mathrm{m}$.), and started treatment with a mean percentage of ultimate height of $93 \cdot 43$. Their mean predicted height was similar to that of the controls, but they only showed a mean increment of $4 \cdot 42$ in. $(11 \cdot 2 \mathrm{~cm}$.), and mean ultimate height after fusion of the epiphyses was nearly 2 inches below that predicted (Table 2). Even with continuous large doses of androgens two of these cases of hypogonadism have become fertile (Foss, 1962).

A comparison of the predicted and ultimate heights in these four groups is shown in Fig. 2, and these figures were submitted to statistical analysis as shown in Table 3.

The only group which is significantly different from the controls is Group C. Group B could quite likely have occurred by chance from a normal 
TREATED, INTENSTYE

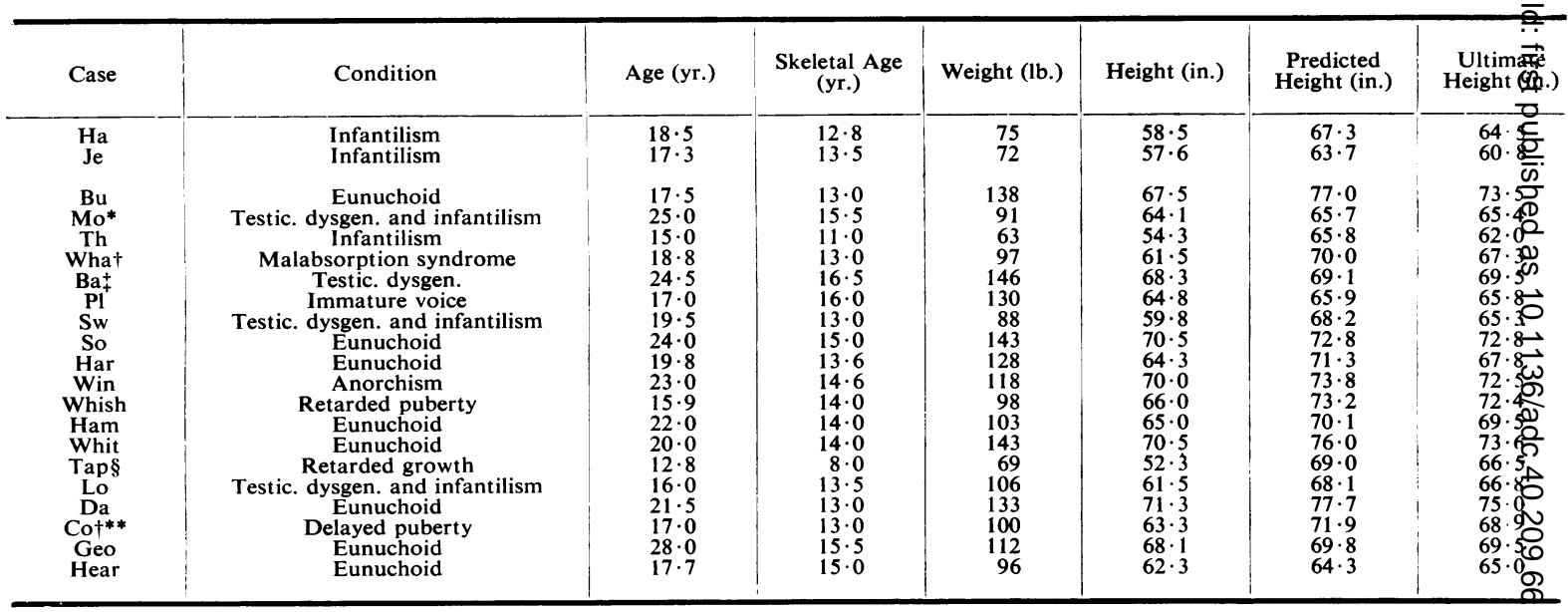

* Epiphyses fused at 39 years after further treatment without further growth.

$\dagger$ These cases had children.

+ Previously given M.T. $15 \mathrm{mg}$./day for 12 months elsewhere.

Follow-up age 26.

** Skeletal age 16 at 19, National Service, final follow-up age 30.

TA ÂRE

MEAN FIGURES IN CONTRQGLS

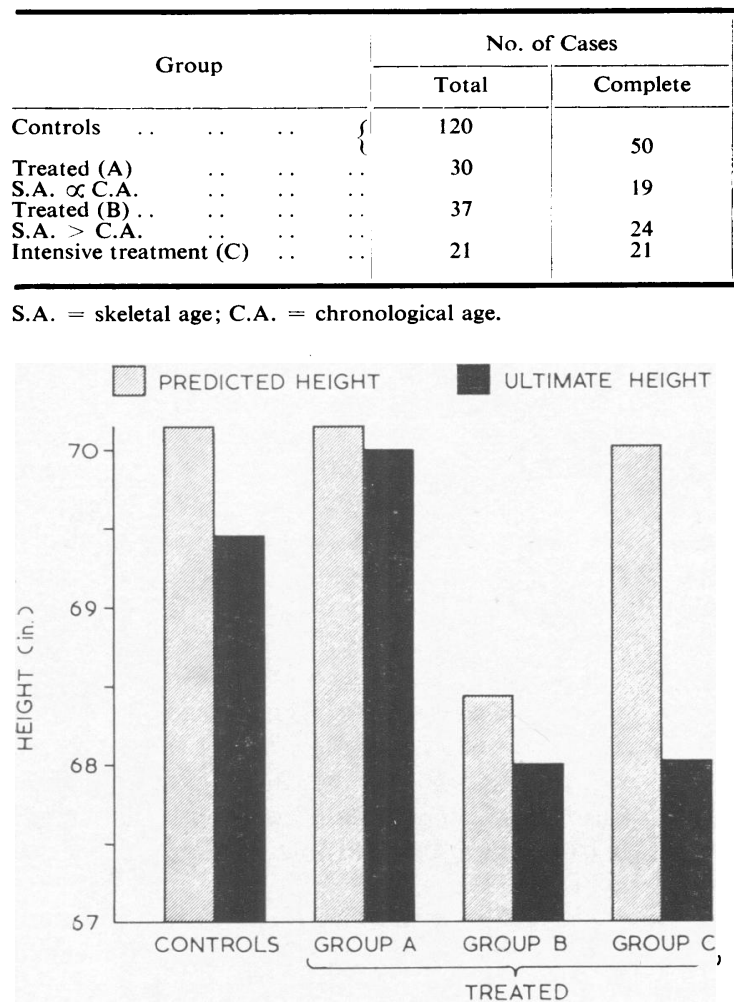

population. Group A compared with the controls did not quite reach the $5 \%$ level of probability.

\section{Discussion}

Sobel et al. (1956) suggest that oral methyl testosterone even in doses of $5 \mathrm{mg}$./day (which they state was as effective a growth promoter as $10-20 \mathrm{mg}$./ day), was in fact a growth inhibitor, despite its immediate action of accelerating growth, as in more than half of their small series of young girls and boys there was disproportionately greater acceleration in skeletal age. They further suggest that there was a lag in development of x-ray evidence of maturation of ossification centres. All their conclusions were based on a short follow-up of two years.

FIG. 2.-A comparison of predicted and ultimate heights in the four groups. 
ANDROGENS, GROUP C

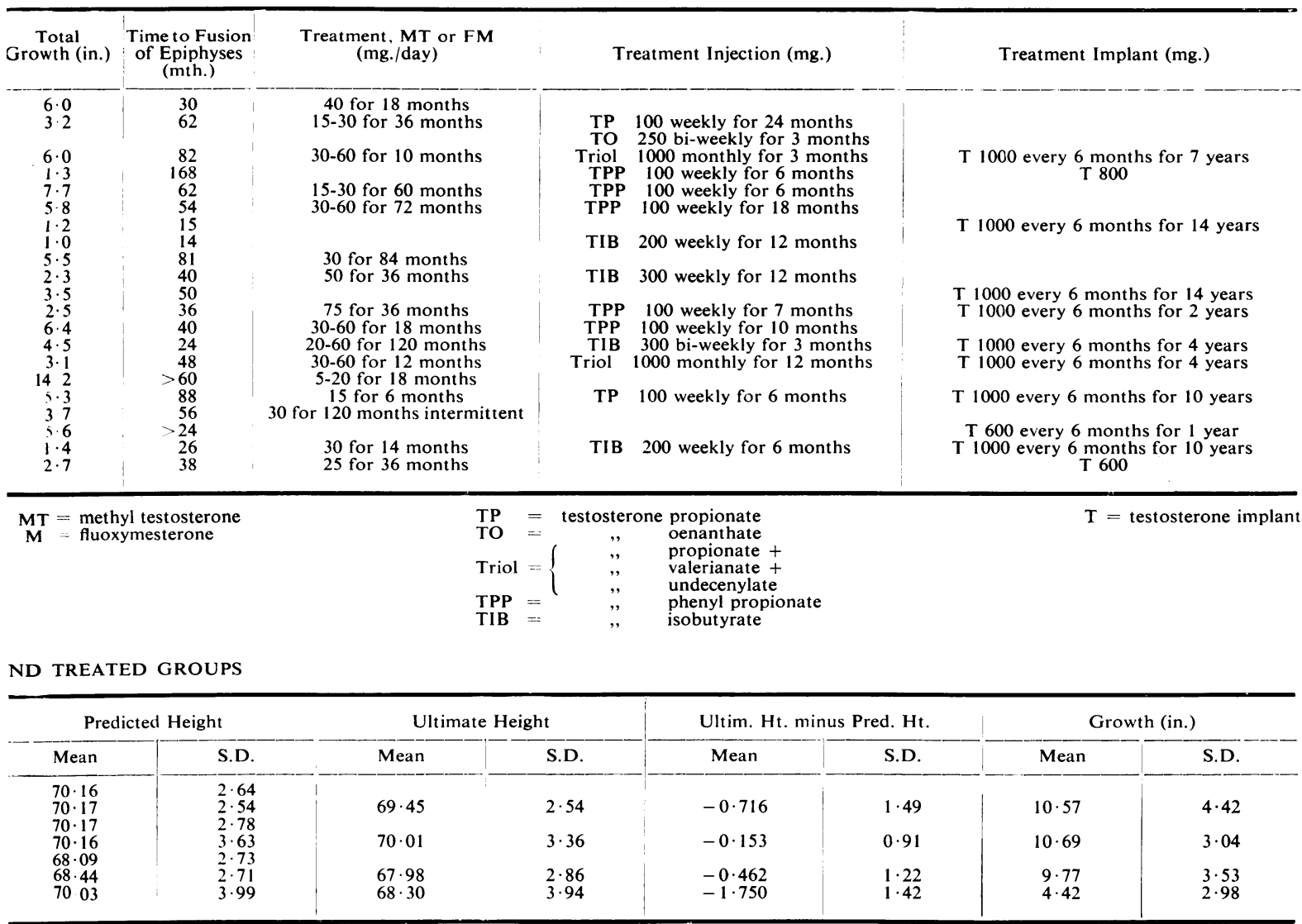

They did not state whether the oral methyl testosterone was merely swallowed or absorbed transmucosally under the tongue or in the buccal pouch. Theoretically absorption through the mucosa of the mouth should increase its efficacy, as some of it by-passes the portal circulation and is not detoxicated by the liver. It was shown that the ratio of effectiveness of transmucosal to orally ingested methyl testosterone in women was $1 \cdot 38: 1$ (Foss, 1956).

The doses of methyl testosterone that they used for these young children were much too high, and produced virilization, and in some, given $40 \mathrm{mg}$./day, treatment was withdrawn after two and a half to

TABLE 3

ULTIMATE HEIGHT MINUS PREDICTED HEIGHT

\begin{tabular}{|c|c|c|c|c|c|c|c|c|}
\hline & \multirow{2}{*}{\multicolumn{2}{|c|}{ Group }} & & \multirow{2}{*}{$\begin{array}{l}\text { No. of } \\
\text { Cases }\end{array}$} & \multirow{2}{*}{$\begin{array}{l}\text { Mean Height } \\
\text { (in.) }\end{array}$} & \multirow{2}{*}{$\begin{array}{l}\text { Standard } \\
\text { Deviation }\end{array}$} & \multicolumn{2}{|c|}{$\begin{array}{l}\text { Comparison of Group Mean } \\
\text { with Control Mean }\end{array}$} \\
\hline & & & & & & & $\mathrm{t}$ & $\mathrm{p}$ \\
\hline $\begin{array}{l}\text { Controls } \\
\text { Treated (A) } \\
\text { (B) } \\
\text { (C) }\end{array}$ & $\begin{array}{l}\cdots \\
\cdots \\
\cdots\end{array}$ & $\begin{array}{l}\cdots \\
\cdots \\
\cdots\end{array}$ & $\begin{array}{l}\ldots \\
\cdots \\
\cdots\end{array}$ & $\begin{array}{l}50 \\
19 \\
24 \\
21\end{array}$ & $\begin{array}{l}-0.716 \\
-0.153 \\
-0.462 \\
-1.750\end{array}$ & $\begin{array}{l}1 \cdot 49 \\
0.91 \\
1 \cdot 22 \\
1.42\end{array}$ & $\begin{array}{l}1 \cdot 901 \\
0 \cdot 726 \\
2 \cdot 709\end{array}$ & $\begin{array}{c}\text { Not significant } \\
\text { Not significant } \\
<0.01\end{array}$ \\
\hline
\end{tabular}


three months. Androgenic effect is dependent on the product of dose and duration of treatment; and whereas their maximum growth acceleration was no greater with doses of more than $5 \mathrm{mg}$./day, on their time/dose schedule of $20 \mathrm{mg}$./day for six months their figures showed a greater average increment in skeletal age. Over such a short follow-up of 2 years this presumably led them to the false assumption that ultimate height would be reduced.

Bayley et al. (1957) included in their study 25 controls for which there were predicted and ultimate heights, and 20 treated cases were similarly followed up. The mean difference for ultimate height minus predicted height was +1 in. $(2 \cdot 54 \mathrm{~cm}$.) for controls, and $+1 \cdot 1$ in. $(2 \cdot 8 \mathrm{~cm}$.) for the treated group.

In the present study, which is about twice as large as that of Bayley et al. (1957), methyl testosterone in doses usually of 5-15 mg. daily for periods of 3-14 months, or 20-75 mg. intermittently for 30 months, did not significantly alter the mean ultimate height or the total mean growth. In two boys on the latter régime, one was $2 \mathrm{in} .(5 \mathrm{~cm}$.) shorter and the other 1 in. $(2 \cdot 54 \mathrm{~cm}$.) taller than their predicted heights.

The group with gross retardation of skeletal age included 9 cases of eunuchoidism, 8 cases of testicular dysgenesis and infantilism, and the rest with delayed puberty. Eight of these cases were over the age of 20 when first seen.

Intensive treatment (Table 1) with large doses of androgens by implantation, injection, and/or by mouth significantly reduced their growth compared with the original prediction. However, these were mostly cases with androgen deficiency, and perhaps cannot be compared with boys with normal testes and of a lower age-group, with a greater expectancy of potential growth. With such gross retardation of skeletal age when first seen, predictions of their ultimate height from the tables of normal boys (Bayley and Pinneau, 1952) are probably open to considerable error.

It is interesting that the assessments of predicted height were slightly more than the ultimate heights in all groups in this series, whereas in Bayley's series it was the reverse. Nevertheless, these results confirm the finding of Bayley et al. (1957) that there is no deleterious effect of methyl testosterone on growth.

The indication for use of androgens in accelerating growth and development in boys without endocrine disorders is limited, and is only warranted when for psychological reasons it is necessary to adjust development to the normal for the chronological age of the boy.
Methyl testosterone in doses of 5-10 mg. daily will achieve this purpose satisfactorily without any fear of reducing expected height, or inhibiting growth.

Whether the lesser virilizing anabolic steroids will increase ultimate height over predicted height is open to conjecture, and this point can only be settled when a sufficient number of cases have been followed up to adult stature. In a series of 35 boys (treated with various anabolic steroids) some of whom have been observed for 6 years, there appears to be no disproportionate epiphysial maturation during the period of treatment.

\section{Summary}

Out of a series of 208 boys whose growth was studied during the past 18 years, final adult height was measured in 114 . Of these, 50 were controls, and their growth and skeletal ages, with height prediction and ultimate heights, were compared with those measurements for 2 groups with normal or retarded skeletal age, treated with methyl testosterone in small to moderate doses for up to 30 months, and for a third group treated intensively with large doses of androgens for longer periods, until epiphysial closure and complete virilization.

In the first two treated groups ultimate growth was not affected, but in the third group ultimate height was reduced by 2 in. $(5 \mathrm{~cm}$.).

I am indebted to the Registrar of the Bristol Executive Council for considerable help in tracing many cases: to Miss Ethel Duncan, Lecturer in Medical Statistics, University of Bristol, for help and advice with the statistical analysis: to Professor A. V. Neale for permission to include results of some of his cases, and to Dr. J. M. Tanner for his very valuable criticism and comments.

\section{REFERENCES}

Bayley, N., Gordan, G. S., and Lisser, H. (1957). Long-term experiences with methyltestosterone as a growth stimulant in short immature boys. Pediat. Clin. N. Amer., 4, 819.

_, and Pinneau, S. R. (1952). Tables for predicting adult height from skeletal age: revised for use with the Greulich-Pyle hand standards. J. Pediat., 40, 432.

Foss, G. L. (1956). A comparison of the relative efficacy of methyltestosterone by the gastric and oral transmucosal routes. J. Endocr., 13, 269.

(1962). Infantilism to fatherhood in the malabsorption syndrome. Brit. med. J., 2, 368.

Greulich, W. W., and Pyle, S. I. (1959). Radiographic Atlas of Skeletal Development of the Hand and Wrist, 2nd ed. Stanford University Press, California; Oxford University Press, London.

Sobel, E. H., Raymond, C. S., Quinn, K. V., and Talbot, N. B. (1956). The use of methyltestosterone to stimulate growth: relative influence on skeletal maturation and linear growth. $J$. clin. Endocr., 16, 241. 